\title{
Thermodynamic Considerations on Gold Dissolution in Different Lixiviants (II)
}

\author{
CATALIN ALEXANDRU BARBU ${ }^{1}$, ION CONSTANTIN ${ }^{1}$, MIHNEA COSMIN COSTOIU ${ }^{1}$, MIHAI BUZATU ${ }^{1}$, AUGUSTIN SEMENESCU ${ }^{2 *}$ \\ 'University Politehnica of Bucharest, 313 Splaiul Independentei, 060021, Bucharest, Romania \\ 'University Politehnica of Bucharest, Faculty of Material Science and Engineering, 313 Splaiul Independentei, 060021, Bucharest, \\ Romania
}

\begin{abstract}
The paper presents the main thermodynamic aspects related to the gold dissolution with thiosulphate, thiourea and thiocyanate. The thermodynamic stability of the gold complexes and the reaction mechanisms thatensure the gold dissolution in the mostrepresentative lixiviants with potential for use in the gold industry are analyzed. The performances of the lixiviants are analyzed in several ways in antithesis with those of the cyanide: ecological, technological and economic.
\end{abstract}

Keywords: gold, alternative lixiviants, thiosulfate, thiourea, thiocyanate, thermodynamics, reaction mechanisms

The need to find alternative lixiviants to cyanide in the gold industry has become more and more stringent lately as a result of growing exigencies in the environmental protection requirements, in particular related to the drastic reduction in the acceptable levels of emissions of hazardous substances discharged into the environment and / or technological by-products stored, considered to be toxic to flora, fauna and humans. Up to now, over 25 new lixiviants have been tested at laboratory, pilot and even industrial scale ranges, of which those with the highest chance of materializing through technologies that substitute cyanide at one point as a result of their perfectioning or increased harshening of the cyanide use conditions are as follows: thiosulphates, thiourea and thiocyanates. This paper aims to present the main aspects related to the thermodynamics and the mechanisms of gold dissolution reactions in the aqueous solutions of thiosulphates, thiourea and thiocyanates.

\section{Thiosulfate Leaching}

Of all the lixiviants proposed for gold dissolution from ores, ammonium and sodium thiosulphates are the most promising due to their ability to dissolve gold in certain conditions at a rate even higher than that of cyanides and to form stable complex compounds in the leaching process but especially because thiosulphates are considered harmless to the environment and are commonly used as fertilizers in agriculture. Under these circumstances, most research worldwide, especially after 1990, when cyanide use became problematic or prohibited in many countries around the world, focused on this lixiviant in order to establish a viable technology to replace the leaching process by cyanidation. Generally, thiosulphates have been proposed for leaching auriferous ores and concentrates considered difficult for cyanidation and which require special pretreatments of pyrometallurgical, hydrometallurgical or biologic pre-cyanidation oxidation such as those containing large amounts of cyanide consuming minerals for instance copper sulphides and other sulphides, the refractory sulfuric, the telluric and coaly ones. One of the reasons that recommend thiosulphates for refractory sulfuric ores is that sulfuric minerals and sulfur only react on the surface with the thiosulphates, which means low consumption of reagents in these reactions, unlike cyanides that react more easily with certain sulphides and sulfur.
In oxidizing aqueous solutions sulfur is a very active element, forming a lot of anions, more or less thermodynamically stable, corresponding to the oxidation states from -2 to +7 . The anions of thiosulphate $\left(\mathrm{S}_{2} \mathrm{O}_{3}{ }^{2-}\right)$, are formed from the two-step dissociation of the thiosulfuric acid $\left(\mathrm{H}_{2} \mathrm{~S}_{2} \mathrm{O}_{3}\right)$ according to the reactions:

$$
\begin{aligned}
\mathrm{H}_{2} \mathrm{~S}_{2} \mathrm{O}_{3} & \rightarrow H^{+}+\mathrm{HS}_{2} \mathrm{O}_{3}^{-} ; & & p K_{a_{1}}=0,3 \\
\mathrm{HS}_{2} \mathrm{O}_{3}^{-} & \rightarrow H^{+}+\mathrm{S}_{2} \mathrm{O}_{3}^{2-} ; & & p K_{a_{2}}=1,7
\end{aligned}
$$

where pKa is the decimal logarithm of the changed sign dissociation reaction constant.

The metastable compounds of sulfur that can be formed in aqueous solutions are shown in the Pourbaix diagram of the metastable system $\mathrm{S}-\mathrm{H}_{2} \mathrm{O}$ presented in Figure 1 . The main metastable anions of sulfur indicated by this diagram, depending on the $\mathrm{pH}$ and the standard reduction potential from the solution, are thiosulfate $\left(\mathrm{S}_{2}{ }_{3}{ }^{2-}\right)$, sulfite $\left(\mathrm{SO}^{2-}\right)$, polythionates $\left(\mathrm{S}_{\mathrm{n}} \mathrm{O}^{2-}, \mathrm{n}=2 \ldots . .5\right)$ ) and sulfur ( $\left.\mathrm{S}^{2-}\right)$. It should be noted that the sulfate and bisulfate were not included in this diagram because they are less thermodynamically stable than thiosulphate, polythionates, sulfite, sulfurous hydrogen and sulfurous acid. According to the diagram, thiosulphate occupies an elongated stability field, which narrows with the $\mathrm{pH}$ increase of the solution and, being a metastable anion, tends to decompose chemically. Depending on the $\mathrm{pH}$ and the potential of the solutions, the thiosulphate can oxidize with sulphite formation, polythionates ( especially tetrathionate $\mathrm{S}_{4} \mathrm{O}^{2-}$ ) and sulfate and / or can be reduced to elemental sulfur $\left(S^{\circ}\right)$ and sulfur anions $\left(\mathrm{S}^{2}\right)$. Other polythionates that can form from the thiosulfate oxidation are trithionate $\left(\mathrm{S}_{3} \mathrm{O}_{6}{ }^{2-}\right)$ and pentathionate $\left(\mathrm{S}_{5} \mathrm{O}_{6}{ }^{2}\right)$, but they do not appear in Figure 1 because they are less stable than tetrathionate and thiosulphate.

The main redox reactions to which thiosulfate can participate are shown in Table 1. Reactions 1-5 from Table 1 show that the thiosulfate ions can be oxidized by the divalent copper ions, the trivalent iron ions, and the oxygen dissolved in the solution, which will increase the consumption of reagents in the leaching processes with thiosulphates. Reactions 6 and 7 highlight the thiosulphate tendency to disproportionate with elemental sulfur and sulfur dioxide formation in acidic media, respectively of

*email: asemenescu2002@yahoo.com 


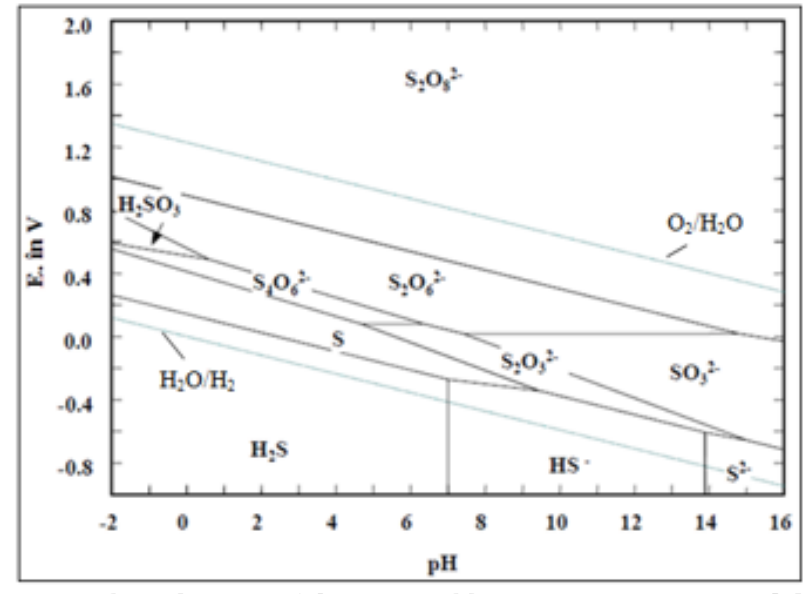

Fig. 1. Pourbaix diagram of the metastable system $\mathrm{S}-\mathrm{H} 2 \mathrm{O}$ at $25^{\circ} \mathrm{C}$ [1] $[\mathrm{S}]=1 \mathrm{M}$

sulfate and sulfur anions in basic media. Also, reactions 12 and 13 show that the addition of sulfur or sulphite ions inhibits the decomposition of thiosulphate ions, thus increasing their stability. As a result, in thiosulphate leaching processes, particular consideration should be given to the side reactions to which thiosulphate anions can take part, as they have an important effect on the consumption of reagents and, implicitly, on gold extraction. Generally, even if thiosulphate anions have a reduced stability, there still is a stable salts series of these in aqueous solutions, the most known and used being sodium thiosulphate $\left(\mathrm{Na}_{2} \mathrm{~S}_{2} \mathrm{O}_{3} .5\right.$ $\mathrm{H}_{2} \mathrm{O}$ ) and ammonium thiosulfate $\left(\mathrm{NH}_{4}\right)_{2} \mathrm{~S}_{2} \mathrm{O}_{3}$.

Thiosulphate anions have the ability to form stable complex ions in aqueous solutions with a series of metals, such as Au, Ag, Cu, Fe, Cd, Ni, Co, Pd, Pb, Zn etc. (Table 2).

According to the data presented in Table 2, gold forms in the aqueous solutions containing thiosulfate anions two complex anions $\mathrm{Au}\left(\mathrm{S}_{2} \mathrm{P}_{3}\right)_{2}{ }^{3-}$ and $\mathrm{Au}\left(\mathrm{S}_{2} \mathrm{P}_{3}\right)_{2}$ corresponding to valency states +1 , respectively +3 ; the first one, which is more stable than the second, is formed according to the reaction:

$$
\mathrm{Au}+2 \mathrm{~S}_{2} \mathrm{O}_{3}^{2-} \rightarrow \mathrm{Au}\left(\mathrm{S}_{2} \mathrm{O}_{3}\right)_{2}^{3-}+e ; \quad E^{0}=-0,153 \mathrm{~V}
$$

Gold dissolution the after this reaction requires the presence of an oxidizer in the solution for taking over the released electron.

Given the low potential $(-0.153 \mathrm{~V})$, the role of oxidizer can be played by a weak oxidizer, such as the oxygen dissolved in the solution, when the global/overall dissolution reaction of gold in the thiosulphate solutions becomes:

$$
\begin{gathered}
\mathrm{Au}+2 \mathrm{~S}_{2} \mathrm{O}_{3}^{2-} \rightarrow \mathrm{Au}\left(\mathrm{S}_{2} \mathrm{O}_{3}\right)_{2}^{3-}+e ; \\
1 / 4 \mathrm{O}_{2}+1 / 2 \mathrm{H}_{2} \mathrm{O}+e \rightarrow \mathrm{OH}^{-} \quad E_{2}^{0}=-0,153 \mathrm{~V} \\
\hline
\end{gathered}
$$$$
\mathrm{Au}+2 \mathrm{~S}_{2} \mathrm{O}_{3}^{2-}+1 / 4 \mathrm{O}_{2}+1 / 2 \mathrm{H}_{2} \mathrm{O} \rightarrow \mathrm{Au}\left(\mathrm{S}_{2} \mathrm{O}_{3}\right)_{2}^{3-}+\mathrm{OH}^{-} \mathrm{E}^{0}=0,248 \mathrm{~V}
$$

The positive value of the potential shows that the gold dissolution reaction with thiosulphate in the presence of the oxygen is thermodynamically possible.

However, the global/overall gold dissolution reaction is very slow and, in order to accelerate it, it is necessary to have a catalyst, such as divalent copper, trivalent iron or divalent nickel salts. The use of trivalent iron ions as a catalyst is contraindicated because in the thiosulphate solutions they are unstable at $\mathrm{pH}$ higher than 8 [3] .

The most suitable catalyst for gold dissolution in thiosulphate solutions has been proved to be divalent copper (in the form of various salts, but especially of sulphate) in combination with ammonia as a stabilizer of the bivalent copper species as tetraamine cations $\left(\mathrm{Cu}\left(\mathrm{NH}_{3}\right)_{4}^{2+}\right)$, which are formed from the reaction of copper ions with ammonia:

$$
\mathrm{Cu}^{2+}+4 \mathrm{NH}_{3} \rightarrow \mathrm{Cu}\left(\mathrm{NH}_{3}\right)_{4}^{2+}
$$

It is appreciated [4] that the rate of gold leaching in the presence of bivalent copper ions and ammonia increases up to 20 times compared to the situation where the

\begin{tabular}{|c|c|c|}
\hline No. & Reaction & $\Delta G_{298}^{0}, \mathrm{~kJ} / \mathrm{mol}$ \\
\hline 1 & $2 \mathrm{~S}_{2} \mathrm{O}_{3}^{2-}+2 \mathrm{Cu}^{2+}=\mathrm{S}_{4} \mathrm{O}_{6}^{2-}+2 \mathrm{Cu}^{+}$ & $-14,1$ \\
\hline 2 & $2 \mathrm{~S}_{2} \mathrm{O}_{3}^{2-}+2 \mathrm{Fe}^{3+}=\mathrm{S}_{4} \mathrm{O}_{6}^{2-}+2 \mathrm{Fe}^{2+}$ & $-133,3$ \\
\hline 3 & $2 \mathrm{~S}_{2} \mathrm{O}_{3}^{2-}+1 / 2 \mathrm{O}_{2}+\mathrm{H}_{2} \mathrm{O}=\mathrm{S}_{4} \mathrm{O}_{6}^{2-}+2 \mathrm{OH}^{-}$ & $-61,9$ \\
\hline 4 & $3 \mathrm{~S}_{2} \mathrm{O}_{3}^{2-}+2 \mathrm{O}_{2}+\mathrm{H}_{2} \mathrm{O}=2 \mathrm{~S}_{3} \mathrm{O}_{6}^{2-}+2 \mathrm{OH}^{-}$ & $-437,2$ \\
\hline 5 & $\mathrm{~S}_{2} \mathrm{O}_{3}^{2-}+2 \mathrm{O}_{2}+2 \mathrm{OH}^{-}=2 \mathrm{SO}_{4}^{2-}+\mathrm{H}_{2} \mathrm{O}$ & $-887,8$ \\
\hline 6 & $\mathrm{~S}_{2} \mathrm{O}_{3}^{2-}+2 \mathrm{H}^{+}=\mathrm{SO}_{2}+\mathrm{S}^{0}+\mathrm{H}_{2} \mathrm{O}$ & $-18,7$ \\
\hline 7 & $\mathrm{~S}_{2} \mathrm{O}_{3}^{2-}+2 \mathrm{OH}^{-}=\mathrm{SO}_{4}^{2-}+\mathrm{S}^{2-}+\mathrm{H}_{2} \mathrm{O}$ & $-53,8$ \\
\hline 8 & $\mathrm{~S}_{3} \mathrm{O}_{6}^{2-}+\mathrm{H}_{2} \mathrm{O}=\mathrm{S}_{2} \mathrm{O}_{3}^{2-}+\mathrm{SO}_{4}^{2-}+2 \mathrm{H}^{+}$ & $-65,5$ \\
\hline 9 & $2 \mathrm{~S}_{3} \mathrm{O}_{6}^{2-}+6 \mathrm{OH}^{-}=\mathrm{S}_{2} \mathrm{O}_{3}^{2-}+4 \mathrm{SO}_{3}^{2-}+3 \mathrm{H}_{2} \mathrm{O}$ & $-313,3$ \\
\hline 10 & $\mathrm{~S}_{4} \mathrm{O}_{6}^{2-}+2 \mathrm{OH}^{-}=\mathrm{S}_{2} \mathrm{O}_{3}^{2-}+\mathrm{SO}_{4}^{2-}+\mathrm{S}^{0}+\mathrm{H}_{2} \mathrm{O}$ & $-161,2$ \\
\hline 11 & $4 \mathrm{~S}_{4} \mathrm{O}_{6}^{2-}+6 \mathrm{OH}^{-}=5 \mathrm{~S}_{2} \mathrm{O}_{3}^{2-}+2 \mathrm{~S}_{3} \mathrm{O}_{6}^{2-}+3 \mathrm{H}_{2} \mathrm{O}$ & $-189,4$ \\
\hline 12 & $2 \mathrm{~S}_{5} \mathrm{O}_{6}^{2-}+6 \mathrm{OH}^{-}=5 \mathrm{~S}_{2} \mathrm{O}_{3}^{2-}+3 \mathrm{H}_{2} \mathrm{O}$ & $-449,7$ \\
\hline 13 & $4 \mathrm{SO}_{3}^{2-}+2 \mathrm{~S}^{2-}+3 \mathrm{H}_{2} \mathrm{O}=3 \mathrm{~S}_{2} \mathrm{O}_{3}^{2-}+6 \mathrm{OH}^{-}$ & $-29,5$ \\
\hline 14 & $\mathrm{~S}_{4} \mathrm{O}_{6}^{2-}+\mathrm{SO}_{3}^{2-}+2 \mathrm{OH}^{-}=2 \mathrm{~S}_{2} \mathrm{O}_{3}^{2-}+\mathrm{SO}_{4}^{2-}+\mathrm{H}_{2} \mathrm{O}$ & $-194,3$ \\
\hline 15 & $\mathrm{~S}_{2} \mathrm{O}_{3}^{2-}+\mathrm{S}_{3} \mathrm{O}_{6}^{2-}=\mathrm{S}_{4} \mathrm{O}_{6}^{2-}+\mathrm{SO}_{3}^{2-}$ & $-31,0$ \\
\hline 16 & $\mathrm{SO}_{3}^{2-}+\mathrm{S}_{5} \mathrm{O}_{6}^{2-}=\mathrm{S}_{4} \mathrm{O}_{6}^{2-}+\mathrm{S}_{2} \mathrm{O}_{3}^{2-}$ & $-99,1$ \\
\hline & & \\
\hline
\end{tabular}

Table 1

REDOX REACTIONS OF THIOSULFATE [2] 


\begin{tabular}{|c|c|c|c|}
\hline Complex & lg $\beta$ & Complex & lg $\beta$ \\
\hline $\mathrm{Au}^{+}+2 \mathrm{~S}_{2} \mathrm{O}_{3}^{2-}=\mathrm{Au}\left(\mathrm{S}_{2} \mathrm{O}_{3}\right)_{2}^{3-}$ & 26,0 & $\mathrm{Cu}^{+}+\mathrm{S}_{2} \mathrm{O}_{3}^{2-}=\mathrm{Cu}\left(\mathrm{S}_{2} \mathrm{O}_{3}\right)^{-}$ & 10,4 \\
\hline $\mathrm{Au}^{+}+\mathrm{S}_{2} \mathrm{O}_{3}^{2-}=\mathrm{Au}\left(\mathrm{S}_{2} \mathrm{O}_{3}\right)^{-}$ & 10,4 & $\mathrm{Cu}^{+}+2 \mathrm{~S}_{2} \mathrm{O}_{3}^{2-}=\mathrm{Cu}\left(\mathrm{S}_{2} \mathrm{O}_{3}\right)_{2}^{3-}$ & 12,3 \\
\hline $\mathrm{Ag}^{+}+\mathrm{S}_{2} \mathrm{O}_{3}^{2-}=\mathrm{Ag}\left(\mathrm{S}_{2} \mathrm{O}_{3}\right)^{-}$ & 9,2 & $\mathrm{Cu}^{+}+3 \mathrm{~S}_{2} \mathrm{O}_{3}^{2-}=\mathrm{Cu}\left(\mathrm{S}_{2} \mathrm{O}_{3}\right)_{3}^{5-}$ & 13,7 \\
\hline $\mathrm{Ag}^{+}+2 \mathrm{~S}_{2} \mathrm{O}_{3}^{2-}=\mathrm{Ag}\left(\mathrm{S}_{2} \mathrm{O}_{3}\right)_{2}^{3-}$ & 12,5 & $\mathrm{Cu}^{2+}+2 \mathrm{~S}_{2} \mathrm{O}_{3}^{2-}=\mathrm{Cu}\left(\mathrm{S}_{2} \mathrm{O}_{3}\right)_{2}^{2-}$ & 4,6 \\
\hline $\mathrm{Ag}^{+}+3 \mathrm{~S}_{2} \mathrm{O}_{3}^{2-}=\mathrm{Ag}\left(\mathrm{S}_{2} \mathrm{O}_{3}\right)_{3}^{5-}$ & 12,8 & $\mathrm{Fe}^{3+}+\mathrm{S}_{2} \mathrm{O}_{3}^{2-}=\mathrm{Fe}\left(\mathrm{S}_{2} \mathrm{O}_{3}\right)^{+}$ & 1,98 \\
\hline $2 \mathrm{Ag}^{+}+3 \mathrm{~S}_{2} \mathrm{O}_{3}^{2-}=\mathrm{Ag}\left(\mathrm{S}_{2} \mathrm{O}_{3}\right)_{3}^{4-}$ & 24,5 & $\mathrm{Pd}^{2+}+4 \mathrm{~S}_{2} \mathrm{O}_{3}^{2-}=\mathrm{Pd}\left(\mathrm{S}_{2} \mathrm{O}_{3}\right)_{4}^{6-}$ & 35,0 \\
\hline $2 \mathrm{Ag}^{+}+4 \mathrm{~S}_{2} \mathrm{O}_{3}^{2-}=\mathrm{Ag}_{2}\left(\mathrm{~S}_{2} \mathrm{O}_{3}\right)_{4}^{6-}$ & 26,3 & $\mathrm{Hg}^{2+}+3 \mathrm{~S}_{2} \mathrm{O}_{3}^{2-}=\mathrm{Hg}\left(\mathrm{S}_{2} \mathrm{O}_{3}\right)_{3}^{4-}$ & 33,3 \\
\hline $3 \mathrm{Ag}^{+}+4 \mathrm{~S}_{2} \mathrm{O}_{3}^{2-}=\mathrm{Ag}_{3}\left(\mathrm{~S}_{2} \mathrm{O}_{3}\right)_{4}^{5-}$ & 38,2 & $\mathrm{Cd}^{2+}+3 \mathrm{~S}_{2} \mathrm{O}_{3}^{2-}=\mathrm{Cd}\left(\mathrm{S}_{2} \mathrm{O}_{3}\right)_{3}^{4-}$ & 6,4 \\
\hline $3 \mathrm{Ag}^{+}+5 \mathrm{~S}_{2} \mathrm{O}_{3}^{2-}=\mathrm{Ag}_{3}\left(\mathrm{~S}_{2} \mathrm{O}_{3}\right)_{5}^{7-}$ & 39,8 & $\mathrm{~Pb}^{2+}+3 \mathrm{~S}_{2} \mathrm{O}_{3}^{2-}=\mathrm{Pb}\left(\mathrm{S}_{2} \mathrm{O}_{3}\right)_{3}^{4-}$ & 6,2 \\
\hline $6 \mathrm{Ag}^{+}+8 \mathrm{~S}_{2} \mathrm{O}_{3}^{2-}=\mathrm{Ag}_{6}\left(\mathrm{~S}_{2} \mathrm{O}_{3}\right)_{3}^{10-}$ & 78,6 & $\mathrm{Zn}^{2+}+3 \mathrm{~S}_{2} \mathrm{O}_{3}^{2-}=\mathrm{Zn}\left(\mathrm{S}_{2} \mathrm{O}_{3}\right)_{3}^{4-}$ & 3,3 \\
\hline
\end{tabular}

Table 2

STABILITY CONSTANTS OF THIOSULFATE COMPLEXES AT $25^{\circ} \mathrm{C}[2]$ thiosulphate solutions do not contain copper ions or other catalysts. However, because gold can also form complexes with the ammonia in the solution, it is theoretically possible to form concomitantly gold compounds with both the thiosulfate and the ammonia by the reaction:

$$
\mathrm{Au}\left(\mathrm{S}_{2} \mathrm{O}_{3}\right)_{2}^{3-}+2 \mathrm{NH}_{3} \rightarrow \mathrm{Au}\left(\mathrm{NH}_{3}\right)_{2}^{+}+2 \mathrm{~S}_{2} \mathrm{O}_{3}^{2-}
$$

Even if there are not certain thermodynamic data, gold complexes with thiosulphate and ammonia have very close values of the stability constants $\left(\lg \beta_{2}=26\right.$ when forming $\mathrm{Au}\left(\mathrm{S}_{2} \mathrm{O}_{2}\right)^{3}$, respectively $\lg \beta_{2}=19$ when forming $\mathrm{Au}\left(\mathrm{NH}_{3}\right)_{2}{ }^{+}$, which in practice indicates their simultaneous formation. How ever, it has been found that when the concentration of thiosulfate is maintained within an optimum range, given by the compromise between maximizing the dissolution rate of gold and minimizing the oxidation rate of thiosulfate, the predominant complex in the solution is that of the gold with the thiosulfate [4]. This is also confirmed by the Pourbaix diagram of the system Au- $\mathrm{NH}_{3}-\mathrm{S}_{2} \mathrm{O}_{3}{ }^{2-}-\mathrm{H}_{2} \mathrm{O}$, presented in Figure 2, which shows a broad range of $\mathrm{pH}$ values at which the predominant compound between 0 and $0.2 \mathrm{~V}$ potentials is $\mathrm{Au}\left(\mathrm{S}_{2} \mathrm{O}_{2}\right)^{3-}$ and that the formation of the gold complexes with the ammonia requires much higher oxidation potentials. Even if the gold complex with the thiosulphate can form on a large range of $\mathrm{pH}$ values, high $\mathrm{pHs} / \mathrm{pH}$ (over 9) are/is recommended in practical applications because at $p \mathrm{H}<9$, the triamine predominantly forms $\left(\mathrm{Cu}\left(\mathrm{NH}_{3}\right)_{3}^{+}\right)$, which is a weaker catalyst for dissolving gold compared to tetraamine. A particular importance in the leaching processes of auriferous ores in ammoniacal solutions of thiosulphate under the catalytic action of divalent copper ions must be given to the thiosulphate oxidation with the $\mathrm{Cu}^{2+}$ ions with the formation of tetrathionate and monovalent copper, according to reaction 1 from Table 1 . In the presence of tetraamine this reaction becomes:

$$
2 \mathrm{Cu}\left(\mathrm{NH}_{3}\right)_{4}^{2+}+8 \mathrm{~S}_{2} \mathrm{O}_{3}^{2-}=2 \mathrm{Cu}\left(\mathrm{S}_{2} \mathrm{O}_{3}\right)_{3}^{5-}+\mathrm{S}_{4} \mathrm{O}_{6}^{2-}+8 \mathrm{NH}_{3}
$$

Such a reaction leads to an increase in the consumption of thiosulphate as a result of its oxidation.

However, in alkaline ammoniacal solutions, the oxidation of the thiosulphate by the divalent copper is quite slow and varies inversely proportional to the concentration of the ammonium ions, and in aerated solutions the monovalentcopper is rapidly reoxidized to bivalent copper, with the regeneration of the tetraamine and thiosulfate, according to the reaction:
$2 \mathrm{Cu}\left(\mathrm{S}_{2} \mathrm{O}_{3}\right)_{3}^{5-}+8 \mathrm{NH}_{3}+1 / 2 \mathrm{O}_{2}+\mathrm{H}_{2} \mathrm{O}=2 \mathrm{Cu}\left(\mathrm{NH}_{3}\right)_{4}^{2+}+6 \mathrm{~S}_{2} \mathrm{O}_{3}^{2-}+2 \mathrm{OH}^{-}$

Under these conditions, for the global/overall dissolution reaction of gold in the ammoniacal solutions of thiosulphate in the presence of copper ions, the following equation was proposed [6]:

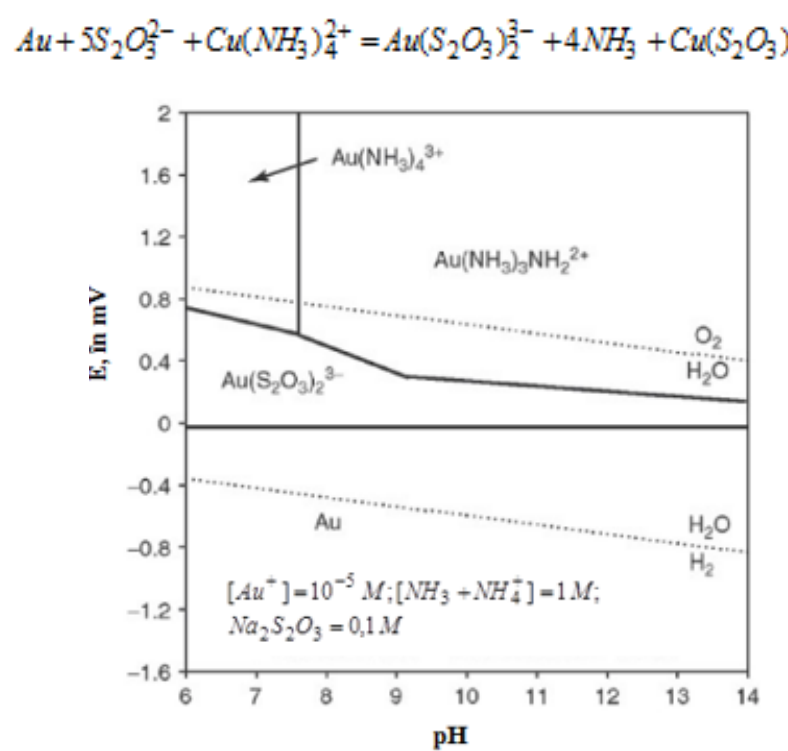

Fig. 2. Pourbaix diagram of the system Au- $\mathrm{NH}_{3}-\mathrm{S}_{2} \mathrm{O}_{3}{ }^{2-}-\mathrm{H}_{2} \mathrm{O}$ at $25^{\circ} \mathrm{C}[5]$

The importance of the ammonia for the stabilization of the bivalent copper ions as tetraamine ions should be emphasized in order to prevent the copper precipitation as hydroxide on the surface of gold, which may lead to its passivation. The gold dissolution mechanism involves three successive stages. In the first stage, the ammoniacal complex of gold is formed as a sum of reactions (a) and (c):

$$
\begin{gathered}
\text { (a) } \mathrm{Au}+2 \mathrm{NH}_{3} \rightarrow \mathrm{Au}\left(\mathrm{NH}_{3}\right)_{2}^{+}+e \\
\text { (c) } \mathrm{Cu}\left(\mathrm{NH}_{3}\right)_{4}^{2+}+e=\mathrm{Cu}\left(\mathrm{NH}_{3}\right)_{2}^{+}+2 \mathrm{NH}_{3} \\
\mathrm{Au}+\mathrm{Cu}\left(\mathrm{NH}_{3}\right)_{4}^{2+} \rightarrow \mathrm{Au}\left(\mathrm{NH}_{3}\right)_{2}^{+}+\mathrm{Cu}\left(\mathrm{NH}_{3}\right)_{2}^{+}
\end{gathered}
$$

In the second stage, the ammoniacal complex of the copper is stabilized as a complex of the gold with the thiosulfate, following reactions (f) and (b): 


$$
\begin{array}{ll}
\text { (f) } \mathrm{Au}+\mathrm{Cu}\left(\mathrm{NH}_{3}\right)_{4}^{2+} \rightarrow \mathrm{Au}\left(\mathrm{NH}_{3}\right)_{2}^{+}+\mathrm{Cu}\left(\mathrm{NH}_{3}\right)_{2}^{+} \\
\text {(b) } \mathrm{Au}\left(\mathrm{NH}_{3}\right)_{2}^{+}+2 \mathrm{~S}_{2} \mathrm{O}_{3}^{2-} \rightarrow \mathrm{Au}\left(\mathrm{S}_{2} \mathrm{O}_{3}\right)_{2}^{3-}+2 \mathrm{NH}_{3}
\end{array}
$$$$
\text { (g) } \mathrm{Au}+2 \mathrm{~S}_{2} \mathrm{O}_{3}^{2-}+\mathrm{Cu}\left(\mathrm{NH}_{3}\right)_{4}^{2+} \rightarrow \mathrm{Au}\left(\mathrm{S}_{2} \mathrm{O}_{3}\right)_{2}^{3-}+\mathrm{Cu}\left(\mathrm{NH}_{3}\right)_{2}^{+}+2 \mathrm{NH}_{3}
$$

Finally, the ammoniacal ions of the monovalent copper are reoxidized by reaction (d), resulting in the overall/global reaction of the leaching process as a sum of reactions $(\mathrm{g})$ and (d)

$$
\begin{array}{ll}
\text { (g) } \mathrm{Au}+2 \mathrm{~S}_{2} \mathrm{O}_{3}^{2-}+\mathrm{Cu}\left(\mathrm{NH}_{3}\right)_{4}^{2+} \rightarrow \mathrm{Au}\left(\mathrm{S}_{2} \mathrm{O}_{3}\right)_{2}^{3-}+\mathrm{Cu}\left(\mathrm{NH}_{3}\right)_{2}^{+}+2 \mathrm{NH}_{3} \\
\text { (d) } \mathrm{Cu}\left(\mathrm{NH}_{3}\right)_{2}^{+}+2 \mathrm{NH}_{3}+1 / 4 \mathrm{O}_{2}+1 / 2 \mathrm{H}_{2} \mathrm{O} \rightarrow \mathrm{Cu}\left(\mathrm{NH}_{3}\right)_{4}^{2+}+\mathrm{OH}^{-} \\
\mathrm{Au}+2 \mathrm{~S}_{2} \mathrm{O}_{3}^{2-}+1 / 4 \mathrm{O}_{2}+1 / 2 \mathrm{H}_{2} \mathrm{O} \rightarrow \mathrm{Au}\left(\mathrm{S}_{2} \mathrm{O}_{3}\right)_{2}^{3-}+\mathrm{OH}^{-}
\end{array}
$$

\section{Thiourea Leaching}

Thiourea was seen as an potential alternative lixiviant for the replacement of cyanide in the processing of certain types of auriferous ores in the 1980s and 1990s. Currently, although itis considered to be a relatively non-toxic reagent for the environment, which behaves as a plant fertilizer, the interest in the use of thiourea has been greatly diminished due to the suspicion that it is part of the carcinogenic substances category and that it is capable of dissolving in addition to the noble metals heavy metals as well, thus raising environmental problems in the handling and storage of cyanide-like effluents [3].

Thiourea, also called thiocarbamide, is an organosulfuric compound with the formula $\mathrm{SC}\left(\mathrm{NH}_{2}\right)_{2}$ with a structure similar to urea, with the exception that the oxygen atom is replaced by a sulfur atom. Thiourea has a high solubility in aqueous solutions ( $142 \mathrm{~g} / \mathrm{I}$ dissolve in water at $25^{\circ} \mathrm{C}$ ), including the acidic ones, forming stable molecules.

Thiourea is a molecular ligand that has the property of forming with gold in acid medium $(\mathrm{pH}<3)$ a single cationic complex $\left(\mathrm{Au}\left[\mathrm{CS}\left(\mathrm{NH}_{2}\right)_{2}\right]_{2}^{+}\right)$corresponding to the monovalent gold, according to the reaction:

$$
\mathrm{Au}+2 \mathrm{CS}\left(\mathrm{NH}_{2}\right)_{2} \rightarrow \mathrm{Au}\left[\mathrm{CS}\left(\mathrm{NH}_{2}\right)_{2}\right]_{2}^{+}+e \quad E^{0}=-0,38 \mathrm{~V}
$$

The logarithm of the stability constant of the thiourea complex with the gold has values of 22 ... 23.3, indicating its high stability in aqueous solutions.

According to the above reaction, the gold dissolution with the thiourea requires the presence of an oxidizer to take over the electron released. It has been shown that the dissolution of the gold is produced at acceptable rates only at oxidation potentials higher than about $0.5 \mathrm{~V}$ [3]. As a result, oxidizers such as air or oxygen do not satisfy this condition, and consequently stronger oxidizers are needed. To this end, various oxidizers, such as trivalent iron salts, perhydrol, pyrolusite and ozone, have been used, butithas been concluded that the best oxidizer is trivalent iron [7]. The gold dissolution reaction with the thiourea in the presence of the trivalent iron ions is based on the following mechanism:

$$
\begin{gathered}
\text { (1) } \mathrm{Au}+2 \mathrm{CS}\left(\mathrm{NH}_{2}\right)_{2} \rightarrow \mathrm{Au}\left[\mathrm{CS}\left(\mathrm{NH}_{2}\right)_{2}\right]_{2}^{+}+e \quad E_{1}^{0}=-E^{0}=-0,38 \mathrm{~V} \\
\text { (2) } \mathrm{F} \epsilon^{3+}+e \rightarrow \mathrm{Fe}^{2+} \quad E_{2}^{0}=+0,77 \mathrm{~V}
\end{gathered}
$$

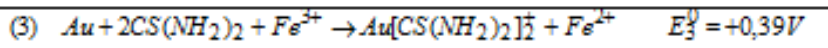

It can be noticed that the gold dissolution reaction with thiourea in the presence of trivalent iron ions is possible $(E>0)$, but its high anodic potential $(0.39 \mathrm{~V})$ makes it possible to simultaneously oxidize the thiourea, which at potentials higher than 0.3 volts is oxidized with the formation of formamidine disulfide $\left(\mathrm{NH}_{2}(\mathrm{NH}) \mathrm{CSSC}\right.$ $\left.(\mathrm{NH}) \mathrm{NH}_{2}\right)$, according to reaction [8]:
Formamidine disulfide is a stronger oxidizer than trivalent iron ions, which means that it can dissolve gold at least to the same extent as these according to the mechanism:
(5) $2 . A \omega+2 C S\left(M H_{2}\right)_{2}+M H_{2}(M H) \operatorname{cssc}(M H) M H_{2}+2 H^{+} \rightarrow 2 . A v\left(C S\left(M H_{2}\right)_{2}\right)_{2}^{+} E_{5}^{0}=+0,04 V$

It should be taken into account that the thiourea oxidation reaction to formamidine disulfide is reversible, which can lead, under certain conditions, to its decomposition with the thiourea formation, elemental sulfur and cyanamide $(\mathrm{CN}(\mathrm{NH} 2))$, according to reaction [3]:

$$
\mathrm{NH}_{2}(\mathrm{NH}) \mathrm{CSSC}(\mathrm{NH}) \mathrm{NH}_{2} \rightarrow \mathrm{CS}\left(\mathrm{NH}_{2}\right)_{2}+\mathrm{S}^{\mathrm{0}}+\mathrm{CN}\left(\mathrm{NH}_{2}\right)
$$

Also, under the conditions of the high oxidation potentials required for the leaching, it is possible to hydrolyze the thiourea with the formation of urea and the release of sulfurated hydrogen [7]:

$$
\mathrm{CS}\left(\mathrm{NH}_{2}\right)_{2}+\mathrm{H}_{2} \mathrm{O} \rightarrow \mathrm{CO}\left(\mathrm{NH}_{2}\right)_{2}+\mathrm{H}_{2} \mathrm{~S}
$$

These reactions are undesirable because, in addition to increasing the consumption of thiourea through formamidine disulfide, being one of the causes of high reagent consumption in the auriferous ore leaching process with acidic thiourea solutions, through the reaction products (sulfur and hydrogen sulfide/sulfurated hydrogen) they lead to decreasing the rate of gold dissolution and to decreasing its extraction. It is believed that the sulfur precipitates on the surface of the gold and thus produces its passivation, and the hydrogen sulfide/sulfurated hydrogen can cause the gold to reprecipitate from the solution [7].

In order to prevent the decomposition of the formamidine disulfide and to provide optimal leaching conditions, corresponding to a reduced thiourea consumption and high gold extraction, it has been shown that a rigorous control of the oxidizers additions (e.g. trivalent iron ions) is necessary so as to ensure the oxidation of only $50 \%$ of the thiourea to formamidine disulfide [7]. It should be taken into account that the excess of oxidizer increases significantly the reactant consumption. Therefore, in practice, it is necessary to use a stabilizer for reconverting the formamidine disulfide to thiourea. To this end, several methods have been proposed, such as bubbling the solution with sulfur dioxide or introducing sodium metabisulphite (Na2S2O5) in the solution. Sulfur dioxide acts as a very specific reducing agent which does not react with other oxidizers as long as in the solution formamidine disulfide is present $[9,10]$. As a result, the sulfur dioxide oxidizes the formamidine bisulfide with the thiourea formation, before it decomposes with the elemental sulfur formation, according to the reaction:

\section{$\left.\mathrm{NH}_{2}(\mathrm{NH}) \mathrm{CSSCNH}\right) \mathrm{NH}_{2}+\mathrm{SO}_{2}+2 \mathrm{H}_{2} \mathrm{O} \rightarrow 2 \mathrm{CS}\left(\mathrm{NH}_{2}\right)_{2}+\mathrm{SO}_{4}^{--}+2 \mathrm{H}^{+}$}

The high consumption of thiourea in the auriferous ores leaching is also a consequence of the fact that, besides the gold and silver, thiourea also forms stable complex compounds with other metals present in the raw material. The stability constants of the thiourea complexes with different metals are shown in Table 3, which points out that after gold the most stable complexes are those of silver and copper. 


\begin{tabular}{|c|c|c|c|}
\hline Complex & lg $\beta$ & Complex & lg $\beta$ \\
\hline $\mathrm{Au}\left[\mathrm{CS}\left(\mathrm{NH}_{2}\right)_{2}\right]_{2}^{+}$ & 21,75 & $\mathrm{Zr}\left[\mathrm{CS}\left(\mathrm{NH}_{2}\right)_{2}\right]_{2}^{2+}$ & 1,77 \\
\hline $\mathrm{Ag}\left[\mathrm{CS}\left(\mathrm{NH}_{2}\right)_{2}\right]_{2}^{+}$ & 13,1 & $\mathrm{Cd}\left[\mathrm{CS}\left(\mathrm{NH}_{2}\right)_{2}\right]_{4}^{2+}$ & 3,55 \\
\hline $\mathrm{Cu}\left[\mathrm{CS}\left(\mathrm{NH}_{2}\right)_{2}\right]_{4}^{2+}$ & 15,4 & $\mathrm{~Pb}\left[\mathrm{CS}\left(\mathrm{NH}_{2}\right)_{2}\right]_{4}^{2+}$ & 2,04 \\
\hline
\end{tabular}

Table 3

LOGARITHMS OF STABILITY CONSTANTS

OF THIOUREA COMPLEXES [3]

The metallic silver dissolution in acidic thiourea solutions in the presence of trivalent iron ions or formamidine disulfide as oxidizers occurs after reactions similar to those of gold dissolution:

$$
\begin{gathered}
\mathrm{Ag}+2 \mathrm{CS}\left(\mathrm{NH}_{2}\right)_{2}+\mathrm{Fe}^{3+} \rightarrow \mathrm{Ag}\left[\mathrm{CS}\left(\mathrm{NH}_{2}\right)_{2}\right]_{2}^{+}+\mathrm{Fe}^{2+} \\
2 \mathrm{Ag}+2 \mathrm{CS}\left(\mathrm{NH}_{2}\right)_{2}+\mathrm{NH}_{2}(\mathrm{NH}) \mathrm{CSS}(\mathrm{NH}) \mathrm{NH}_{2}+2 \mathrm{H}^{+} \rightarrow 2 \mathrm{Ag}\left(\mathrm{CS}\left(\mathrm{NH}_{2}\right)_{2}\right)_{2}^{+}
\end{gathered}
$$

Although some research [11] has demonstrated that the thiourea decomposition is very slow in the presence of the ferric sulfate added in the solution to provide the required concentration of trivalent iron ions, it is appreciated that the presence of sulfuric minerals, such as copper sulfides, can determine the catalyzation of the redox reactions between the thiourea and trivalent iron ions and, implicitly, the increase in the thiourea consumption if a rigorous control over the excess of the iron ions is not ensured.

\section{Thiocyanate Leaching}

Another lixiviant considered as an alternative to the cyanide replacement is thiocyanate. The name of thiocyanate or rhodanide is given to anions. These are formed from the reactions of the cyanide anions with the elemental sulfur or the thiosulfate anions:

$$
\begin{gathered}
\mathrm{CN}^{-}+\mathrm{S}^{0} \rightarrow \mathrm{SCN}^{-} \\
\mathrm{CN}^{-}+\mathrm{S}_{2} \mathrm{O}_{3}^{2-} \rightarrow \mathrm{SCN}^{-}+\mathrm{SO}_{3}^{2-}
\end{gathered}
$$

The most well-known salts of thiocyanate are sodium thiocyanate (NaSCN) and potassium thiocyanate (KSCN).

Thiocyanate has the ligand property for gold, with which it forms soluble, stable and complex ions in the acidic solutions of thiocyanate: aurothyocianate and aurithyocianate, according to the reactions:

$$
\begin{array}{ll}
2 S C N^{-}+A u^{+} \rightarrow A u(S C N)_{2}^{-} & \lg \beta_{2}=17,1 \\
4 S C N^{-}+A u^{3+} \rightarrow A u(S C N)_{4}^{-} & \lg \beta_{4}=42
\end{array}
$$

The high values of the two constants indicate a high stability of gold complexes in thiocyanate solutions. The formation of one or the other complex depends on the concentration of thiocyanate in the solution and on the oxidation potential of the solution.

Decreasing the concentration of the thiocyanate in the solution requires higher oxidation potentials for the aurothiocyanate to be stable. Under standard conditions (concentrations of all species of $1 \mathrm{M}$ to $25^{\circ} \mathrm{C}$ ), gold dissolution reactions and their standard production potentials are:

$$
\begin{gathered}
A u\left(\mathrm{SCN}_{2}^{-}+e=A u+2 \mathrm{SCN}^{-} \quad E^{0}=+0,691 \mathrm{~V}\right. \\
\mathrm{Au}(\mathrm{SCN})_{4}^{-}+3 e \rightarrow A u+4 S \mathrm{SN}^{-} \quad E^{0}=+0,659 \mathrm{~V}
\end{gathered}
$$

where $\mathrm{E}^{\circ}$ is the standard reduction potential.

Therefore, both reactions can only be produced in the presence of a strong oxidizer so as to provide to the solution high enough oxidation potentials required to take over the electrons released by the anodic reactions of the gold dissolution. Solutions bubbling with air or oxygen cannot provide such oxidation potentials, stronger oxidizers being necessary. Of these, it is believed that trivalent iron ions, introduced as ferrous sulfate, are best suited for gold leaching in acidic thiocyanate solutions, according to the reactions:

$$
\begin{gathered}
\text { (1) } A u+2 S C N^{-} \rightarrow A u(S C N)_{2}^{-}+e \quad E_{1}^{0}=-E^{0}=-0,691 \mathrm{~V} \\
\text { (2) } \mathrm{Fe}^{3+}+e \rightarrow F e^{2+} \quad E_{2}^{0}=+0,771 \mathrm{~V} \\
\text { (3) } \mathrm{Au}+2 \mathrm{SCN}^{-}+\mathrm{Fe}^{3+} \rightarrow A u(S C N)_{2}^{-}+\mathrm{Fe}^{2+} \quad E_{3}^{0}=E_{1}^{0}+E_{2}^{0}=+0,08 \mathrm{~V} \\
\text { (4) } \mathrm{Au}+4 \mathrm{SCN}^{-} \rightarrow A u(S C N)_{4}^{-}+3 e \quad E_{4}^{0}=-E^{0}=-0,659 \mathrm{~V} \\
\text { (2) } 3 \mathrm{Fe}^{3+}+3 e \rightarrow 3 \mathrm{Fe}^{2+} \quad E_{2}^{0}=+0,771 \mathrm{~V} \\
\text { (5) } \mathrm{Au}+4 \mathrm{SCN}^{-}+3 \mathrm{Fe}^{3+} \rightarrow A u(S C N)_{4}^{-}+3 \mathrm{Fe}^{2+} \quad E_{5}^{0}=E_{4}^{0}+E_{2}^{0}=+0,112 \mathrm{~V}
\end{gathered}
$$

The thermodynamic analysis of the metallic gold dissolution reactions with thiocyanate solutions shows that they occur at near potentials, respectively $0.6-0.7 \mathrm{~V}$, with the formation of the aurous or auric complexes, depending on the thiocyanate concentration and the oxidizing potential of the solution.

The auriferous ores leaching with acid solutions of thiocyanate in the presence of ferric sulfate as oxidizer raises soe problems related to the need to avoid the hydrolysis of the ferric hydroxide or the thiocyanic acid (HSCN), to the ability of the trivalent iron ions of oxidizing the thiocyanate and the thiocyanate thermodynamic instability at high oxidizing potentials.
At very high acidity values $(\mathrm{pH}<1)$, the hydrolysis of the thiocyanate ions with the thiocyanic acid formation can occur, and at lower acidities ( $\mathrm{pH}>3$ ) the hydrolysis of the trivalent iron takes place, according to the reactions:

$$
\begin{gathered}
\mathrm{SCN}^{-}+\mathrm{H}_{2} \mathrm{O} \rightarrow \mathrm{HSCN}+\mathrm{OH}^{-} \\
\mathrm{Fe}_{2}\left(\mathrm{SO}_{4}\right)_{3}+6 \mathrm{H}_{2} \mathrm{O} \rightarrow 2 \mathrm{Fe}(\mathrm{OH})_{3}+3 \mathrm{H}_{2} \mathrm{SO}_{4}
\end{gathered}
$$

Hence, for gold leaching in acidic thiosulphate solutions, acidities in the $\mathrm{pH}$ range of 1.5 to 2.5 are required.

Since thiocyanate is not stable under certain oxidizing conditions, it can be oxidized with the ferric ion with the formation of sulphate, carbonate and ammonium ions, according to reaction [12]:

$$
\mathrm{SCN}^{-}+8 \mathrm{Fe}^{3+}+7 \mathrm{H}_{2} \mathrm{O} \rightarrow \mathrm{SO}_{4}^{2-}+\mathrm{CO}_{3}^{2-}+\mathrm{NH}_{4}^{+}+8 \mathrm{Fe}^{2+}+10 \mathrm{H}^{+} ; \Delta \mathrm{G}_{298}^{0}=-378,5 \mathrm{~kJ} / \mathrm{mol}
$$


However, it has been shown that the thiocyanate decomposition by oxidation with the trivalent iron ions in the solution is very slow due to the formation of intermediate products from the thiocyanate oxidation, such

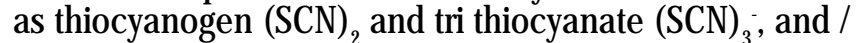
or stable complexes of the thiocyanate with the trivalent iron ions, according to reactions [12] :

$$
\begin{array}{ll}
\left(\mathrm{SCN}_{2}+2 e \rightarrow 2 \mathrm{SCN}^{-}\right. & E^{0}=+0,73 \mathrm{~V} \\
(\mathrm{SCN})_{3}^{-}+2 e \rightarrow 3 \mathrm{SCN}^{-} & E^{0}=+0,65 \mathrm{~V}
\end{array}
$$

Since the standard potentials of the thiocyanate oxidation are lower than that of the trivalent iron oxidation to divalentiron $(0.771 \mathrm{~V})$, the trivalentiron ions may oxidize the thiocyanate with the thiocyanogen and / or tri thiocyanate formation. However, thiocyanogen and tri thiocyanate are unstable in aqueous solutions and hydrolyze by the reactions:

$$
\begin{gathered}
3(\mathrm{SCN})_{2}+4 \mathrm{H}_{2} \mathrm{O} \rightarrow 5 \mathrm{SCN}^{-}+\mathrm{HCN}+\mathrm{SO}_{4}^{2-}+7 \mathrm{H}^{+} \\
(\mathrm{SCN})_{3}^{-}+4 \mathrm{H}_{2} \mathrm{O} \rightarrow 2 \mathrm{SCN}^{-}+\mathrm{HCN}+\mathrm{SO}_{4}^{2-}+7 \mathrm{H}^{+}
\end{gathered}
$$

The resulting hydrogen cyanide is unstable at high oxidizing potentials, such as those required to leach gold with thiocyanate, and oxidizes with the formation of carbonate, ammonium and hydrogen ions:

$$
\mathrm{HCN}+3 \mathrm{H}_{2} \mathrm{O} \rightarrow \mathrm{CO}_{3}^{2-}+\mathrm{NH}_{4}^{+}+3 \mathrm{H}^{+}
$$

Other reactions that can lead to the thiocyanate oxidation are [3]:

$$
\begin{gathered}
\mathrm{SCN}^{-}+4 \mathrm{H}_{2} \mathrm{O} \rightarrow \mathrm{SO}_{4}^{2-}+\mathrm{CN}^{-}+8 \mathrm{H}^{+}+6 e \\
\mathrm{SCN}^{-}+5 \mathrm{H}_{2} \mathrm{O} \rightarrow \mathrm{SO}_{4}^{2-}+\mathrm{CNO}^{-}+10 \mathrm{H}^{+}+8 e \\
\mathrm{SCN}^{-}+7 \mathrm{H}_{2} \mathrm{O} \rightarrow \mathrm{SO}_{4}^{2-}+\mathrm{CO}_{3}^{2-}+\mathrm{NH}_{3}+11 \mathrm{H}^{+}+8 e
\end{gathered}
$$

It is also well known that thiocyanate can form a series of stable complexes with the trivalent iron salts according to the reaction:

$$
\mathrm{Fe}^{3+}+n \mathrm{SCN}^{-} \rightarrow \mathrm{Fe}(\mathrm{SCN})_{n}^{3-n} \quad n=1,2,3,4,5
$$

The formation of the iron thiocyanates may reduce the oxidation potential of the trivalent iron ions and the free thiocyanate concentration from the solution, which will reduce the dissolution rate of gold.

It should be noted that some sulphides such as pyrite, chalcopyrite and galena catalyze the redox reactions between the thiocyanate and the trivalent iron ions [13]. Also, under certain leaching conditions, thiocyanate forms insoluble solid salts with the monovalent copper ions (CuSCN) and with the monovalent silver (AgSCN), but at high concentrations of free thiocyanate, soluble complexes can be formed, respectively $\mathrm{Cu}(\mathrm{SCN})_{3}^{-}$or $\mathrm{Cu}(\mathrm{SCN})_{2}^{-}$.

The formation of copper complexesleads to an increase in thiocyanate consumption and solutions impurification, and the fact that silver can also appear as an insoluble solid salt can cause silver to be irrecoverable by leaching with acidic solutions of thiocyanate [3].

\section{Conclusions on Alternative Lixiviants}

Intense research into finding alternative lixiviants to the conventional cyanidation leaching process of auriferous ores has led to the identification of several reagents capable of dissolving gold under certain conditions, among which the most important due to their performances are: the thiosulphates, thiourea, thiocyanates and halogens. The performances of the lixiviants are analyzed in several ways in antithesis with those of the cyanide: ecological, technological and economic. The environmental considerations address the technological emissions of hazardous substances to health and the environment, the safety in the handling and management of reagents and the effluents toxicity on the environment. The technological criteria mainly address the applicability limits of a reagent, such as the types of ores for which the reagent is adequate, the possibilities for the subsequent recovery of the gold from the solutions, the selectivity of the reagent in the leaching process, etc., the possibilities for recovery and recycling of the reagent, the need and possibilities of the effluents detoxification and the feasibility of industrial scale use of the reagent. The economic criteria that are decisive in most cases include capital expenditures, operating costs, detoxification or recycling costs of reagents, and the management and long-term storage costs of the leaching by-products in tailings ponds.

The toxicity of the chemicals used in different technological processes is appreciated by several indicators, among which the most used are:

- the lethal dose of toxicity LDn defined as the amount of substance that causes the death of $n \%$ of the subjects tested in a set and is usually expressed in $\mathrm{mg} / \mathrm{kg}$ of the body weight of the species tested. More frequently, the average lethal dose is used (LD50);

- the lethal concentration LCn defined as the concentration of a substance in the air or water that causes the killing of $n \%$ of the subjects in a setexposed for a certain time and is expressed as $\mathrm{mg} / \mathrm{m} 3$ or $\mathrm{mg} / \mathrm{l}$ for the specified time. More frequently, the lethal mean concentration for $50 \%$ of the individuals in a set is used (LC50);

- threshold limit value (TLV) defined as the value of the concentration in the air of a substance to which a person may be exposed daily during working hours without adverse effects;

- WGK is a German water quality classification based on its biological characteristics and which divides water in four classes: WGK 0 - uncontaminated water, WGK 1 slightly contaminated water, WGK 2 - contaminated water and WGK 3 - highly contaminated water.

Based on such indicators, a comparison of the lixiviants can be made from the viewpoint of their toxicity. Table 4 presents the toxicity indicators of the main lixiviants used or tested for auriferous ores leaching.

According to the indicators presented in Table 4, it appears that all gold lixiviants present a certain risk of toxicity to personnel and / or the environment. However, the lowest toxicities are presented in the order of thiosulfate, thiocyanate and thiourea, with the consideration that thiourea is considered to be carcinogenic, and the highest risks are recorded in the case of chlorine and cyanide. It should be taken into account that many of the alternative lixiviants require the presence of stronger oxidizers than in the case of cyanide for which air is used as an oxidizer and even the presence of catalysts and stabilizers. In many cases, these supplementary additions result in the formation of compounds with a high potential for toxicity, such as ammonia or hydrogen sulfide/ sulfurated hydrogen. Of all the lixiviants, thiosulphate is considered to be the safest alternative to cyanidation, but it has the disadvantage of high consumption, which can usually be about 5 times higher than in the cyanide case. In addition, given that the price of the sodium thiosulphate is double than that of the ammonium thiosulphate, the ammonium thiosulphate will be economically preferable but which may, however, lead to ammonia emissions with relatively high toxicity indices. At the same time, thiosulphates can spontaneously decompose with the formation of various sulfur compounds, including hydrogen 


\begin{tabular}{|c|c|c|c|c|c|}
\hline Lixiviant & Dose of toxicity & TLV & Toxic concentration & WGK & \multirow{9}{*}{$\begin{array}{c}\text { Table } 4 \\
\text { TOXICITY } \\
\text { INDICATORS OF THE } \\
\text { MAIN LIXIVIANTS [14] }\end{array}$} \\
\hline Sodium cyanide & $\mathrm{LD}_{50}=6,4 \mathrm{mg} / \mathrm{kg}$ & $\begin{array}{c}5 \mathrm{mg} / \mathrm{m}^{3} \text { as } \mathrm{CN} \text { or } \\
10 \mathrm{mg} / \mathrm{m}^{3} \text { equivalent } \\
\mathrm{NaCN}\end{array}$ & $\mathrm{LC}_{50} 0,083 \mathrm{mg} / \mathrm{l}$ for 96 hours & 3 & \\
\hline Hydrogen cyanide & $\mathrm{LD}_{50}=3,7 \mathrm{mg} / \mathrm{kg}$ & $5 \mathrm{mg} / \mathrm{cm}^{3}$ as $C N$ & $\mathrm{LC}_{50}=2,29 \mathrm{mg} / \mathrm{f}$ for 96 hours & 3 & \\
\hline thiosulfate & $\mathrm{LD}_{50}=2890 \mathrm{mg} / \mathrm{kg}$ & - & Ammonia is to be considered & 1 & \\
\hline thiourea & $\begin{array}{c}\mathrm{LD}_{50}=125 \mathrm{mg} / \mathrm{kg} \\
\text { (carcinogenic) }\end{array}$ & - & $\mathrm{LC}_{50}>100 \mathrm{~g} / 1$ & 2 & \\
\hline thiocyanate & $\mathrm{LD}_{50}=764 \mathrm{mg} / \mathrm{kg}$ & - & - & 1 & \\
\hline Ammonia & $\mathrm{LD}_{50}=350 \mathrm{mg} / \mathrm{kg}$ & $14 \mathrm{mg} / \mathrm{m}^{3}$ & $\mathrm{LC}_{50}=0,53 \mathrm{mg} /$ for 96 hours & 2 & \\
\hline $\begin{array}{l}\text { Disulfide } \\
\text { (based on } H_{2} S \text { ) }\end{array}$ & $\begin{array}{c}\mathrm{LC}_{50}=1500 \mathrm{mg} / \mathrm{m}^{3} \text { for } \\
14 \mathrm{~min}\end{array}$ & $15 \mathrm{mg} / \mathrm{m}^{3}$ & $\mathrm{LC}_{50}=1500 \mathrm{mg} / \mathrm{m}^{3}$ for $7 \mathrm{~min}$ & 2 & \\
\hline Chlorine & $\mathrm{LC}_{50}=293 \mathrm{ppm} /$ hour & $1,5 \mathrm{mg} / \mathrm{m}^{3}$ & $\mathrm{LC}_{10}=0,05 \mathrm{mg} /$ for 96 hours & 2 & \\
\hline
\end{tabular}

sulfide/sulfurated hydrogen, with high toxicity. In the case of the thiourea, in addition to being considered carcinogen, if the oxidation potential of the solutions is not maintained within the prescribed limits, there is a risk of the release of the hydrogen sulphides/sulfurated hydrogen which has the TLV close to that of the hydrogen cyanide but which is more difficult to control than the hydrogen cyanide in the leaching process. Chlorine in various forms, although used extensively in the pastfor the treatment of refractory telluric and coaly ores, and as a pretreatment for the oxidation of these types of ores prior to the conventional cyanidation, presents dangerous toxicity indices for the staff health. With the exception of chlorine-based lixiviants that have been used on a commercial scale, the other lixiviants have been tested on a laboratory scale, and only a few of them on a pilot scale or semi-industrial scale, particularly thiosulphates, thiourea and thiocyanates. In general, the testing of alternative lixiviants at a pilot scale has been performed on certain types of ores, for which the conventional cyanide leaching is uneconomic due to the reduced gold extractions or to the excessive cyanide consumption. Even if in some cases, results considered positive have been obtained, their expansion to a significant commercial scale did not take place, especially due to the problems associated to passing from the pilot-level to the commercial level, of which the following have been mentioned [7]:

- the leaching with halogens, thiosulfates and thiourea is very sensitive to the ore mineralogy, which requires frequent corrections of the reagent concentrations to maintain optimum leaching conditions;

- most alternative lixiviants, with the exception of the halogens, at similar concentrations do nothave higher gold dissolution rates than cyanide;

- in all the cases, higher concentrations of the alternative lixiviants compared to cyanidation are required. As a result, for the profitability of the process the recovery and recycling of the lixiviant becomes mandatory;

- technological problems regarding the recovery of the gold from the solution and of the reagents due to their adsorption on different minerals and due to the secondary reactions of the lixiviant with other minerals that form the ore gang;

- leaching with alternative lixiviants is much more complex than cyanidation, making it almost impossible to optimize the operation.

Among the major drawbacks of the major lixiviants with potential for future development the following can be mentioned [15]:

- thiosulfate: the high consumption of reagents, the need for strong oxidizers additions, such as bivalent copper ions and ammonia as their stabilizer, up to now there has not been conceived a simple and accessible/affordable method for the gold extraction from the solution;

- thiourea: carcinogenic, it is more expensive than cyanide, high reagent consumption, difficult gold extraction from the solution;

- chlorine: the need for special stainless-steel equipment or their rubber protection to withstand strongly corrosive oxidizing acidic conditions, the presence of sulphides in the raw material excessively increases the reagent consumption and can lead to the precipitation of gold, the difficult extraction of gold from the solution, silver is nor recovered, gaseous chlorine is extremely toxic.

\section{References}

1.OSSEO-ASARE, K., Solution chemistry and separation process in precious and rare metals system, pp. 113-135, Precious and Rare Metals Technologies, Edited by A.E. Torma and I.H. Guntiler, Elsevier, Amsterdam, 1989;

2.ZHANG, S., Oxidation of refractory gold concentrates and simultaneous dissolution of gold in aerated alkaline solution, Thesis, Murdoch University Weastern Australia, 2004;

3.MARSDEN, J .0, IAIN HOUSE, C., The Chemistry of Gold Extraction, Second Edition, SME, Englewood, Colorado, 2006;

4.AYLMORE, M.G., MUIR, D.M., Tiosulphate leaching-A review, Minerals Engineering, vol.14, pp.135-174, 2001;

5.SENANAYAKE, G., PERERA, W.N., NICOL, M.J., Thermodynamic studies of the gold $(\mathrm{III}) /(\mathrm{I})(0)$ redox system in ammonia-thiosulfate solution at 25 OC, Hydrometallurgy 2003 - Fifth International Conference, Vancouvert, vol.I, TMS-Warrendale P.A., pp. 155-168, 2003;

6.HISKEY, J.B., ATLURI, V.P., Dissolution chemistry of gold and silver in different lixiviants, Mineral Processing and Extractive Metallurgy Review, pp. 95-134, 1988;

7.AYLMORE, M.G., Alternative lixiviants to cyanide for leaching gold ores, Advances in gold ore processing, pp. 501-539, Edited by M.D. Adams, Elsevier, Amsterdam, 2005;

8.GROENEWALD, T., The dissolution of gold in acidic solutions of thiourea, Hydrometallurgy, No.1, pp.277-290, 1976;

9.SCHULZE, R.G., New aspects in thiourea leaching of precious metals, J ournal of Metals, No. 6, pp. 62-65, 1984;

10.YANNOPOULOS, J.C., The Extractive Metallurgy of Gold, Van Nostrand Reinhold, New York, 1991;

11.LI, J., MILLER, J.D., A review of gold leaching in acid thiourea solutions, Mineral Processing and Extractive Metallurgy Review, vol 27, No.3, 2006;

12.LI, J., SAFARZADEH, M.S., MOATS, M.S., MILLER, J.D., LE VIER, K.M., DIETRICH, M., WAN, R.Y., Thiocyanate hydrometallurgy for the recovery of gold. Part I: Chemical and thermodynamic consideration, Hydrometallurgy, vol.113-114, pp.1-9, 2012; 
13.LI, J., WAN, R.Y., LE VIER, K.M., MILLER, J.D., Thiocyanate process for gold recovery, Proceedings of the Sixth International Symposium Hydrometallurgy 2008, Edited by C.G. Anderson and Y. Choi, Society of Mining, Metallurgy and Exploration, Inc., 2008;
14.***http://en.rmgc.ro/Content/uploads/mediu/Annex $\% 205 \mathrm{~B} \% 20$ Processing\%20and\%20Leaching\%20Alternatives.pdf; Rosia Montana Gold Corporation S.A., Flowsheet and leaching alternatives for the Rosia Montana flowsheet, Report, 27 July 2007

15.HILSON, G., MONHEMIUS, A.J., Alternatives to cyanide in the mining industry: What prospects for the future, J ournal of Cleanen Production, vol.14, No. 12-13, pp. 1158-1167, 2006

Manuscript received: 27.07 .2019 